\title{
Autologous platelet concentrate in surgery for macular detachment associated with congenital optic disc pit
}

This article was published in the following Dove Press journal:

Clinical Ophthalmology

22 October 2015

Number of times this article has been viewed

\author{
Jeroni Nadal',2 \\ Marta S Figueroa ${ }^{3}$ \\ Elisa Carreras 2,4 \\ Patricia Pujol ${ }^{2,4}$ \\ Maria Isabel Canut ${ }^{2,4,5}$ \\ Rafael Ignacio Barraquer 2,6 \\ 'Vitreoretinal Surgery Department \\ at Centro de Oftalmología \\ Barraquer, ${ }^{2}$ Universitat autónoma \\ de Barcelona, Barcelona, ${ }^{3}$ Vissum \\ Madrid, Madrid, ${ }^{4}$ Instituto Barraquer, \\ ${ }^{5}$ Glaucoma Department at Centro \\ de Oftalmología Barraquer, ${ }^{6}$ Cornea \\ and Cataract Surgery Department \\ at Centro de Oftalmología Barraquer, \\ Barcelona, Spain
}

Purpose: To evaluate the anatomical and functional results obtained with pars plana vitrectomy (PPV) plus autologous platelet concentrate (APC) as a treatment for macular detachment associated with optic disc pit (ODP).

Methods: We performed a prospective interventional study of 19 eyes of 19 consecutive patients with posterior macular detachment due to ODP. All patients underwent PPV, posterior hyaloid peeling, fluid-air exchange, injection of $0.05 \mathrm{~mL}$ of APC over the ODP and 15\% perfluoropropane (C3F8) endotamponade. Postoperative measures included face-up positioning for 2 hours and then avoidance of the face-up position during the ensuing 10 days. All patients underwent complete ophthalmologic examination and optical coherence tomography preoperatively at 1 month, 3 months, 6 months, 9 months, and 12 months postoperatively and then annually. Outcome measures were best corrected visual acuity (BCVA) by $\log$ MAR, improvement of quality of vision, macular attachment, and resolution of intraretinal schisis-like separation.

Results: Preoperatively, the median BCVA was 0.70 (range: 0.30-1.70) and all patients showed improved visual acuity after surgery; BCVA was 0.22 (range: $0.07-0.52$ ) at 12 months follow-up. All patients showed complete reabsorption of intraretinal fluid (median time: 3.5 months [range: 2-8 months]) and macular attachment at the end of follow-up (median: 60 months [range: 12-144 months]), with stable or improved visual acuity. No reoperations were needed and no major adverse events were recorded.

Conclusion: For macular detachment associated with ODP, the combination of PPV, posterior hyaloid peeling, APC, and C3F8 tamponade is a highly effective alternative technique with stable anatomical and functional results.

Keywords: macular detachment, optic disc pit, maculopathy, retinoschisis, pars plana vitrectomy, autologous platelet concentrate

\section{Introduction}

Optic disc pits (ODPs) are congenital anomalies of the optic nerve head, first described by Wiethe ${ }^{1}$ in 1882 as black cavities on the optic nerve head observed in one eye of a 62-year-old woman. The prevalence of ODP is estimated to be one in every 11,000 patients. $^{2,3}$ In about $70 \%$ of cases, the ODPs are located on the temporal side of the disc and $85 \%-90 \%$ are unilateral. ${ }^{4,5}$ Visual acuity is usually unaffected unless the ODPs are associated with macular pathology, such as macular detachment, retinoschisis-like separation, outer layer macular hole, and retinal pigment epithelial atrophy. Macular detachment develops in one-third to two-thirds of patients, which may occur in childhood or later, the mean being at 30 years of age. ${ }^{6,7}$ Vascular abnormalities such as colobomas and epipapillary membranes may also be associated.
Correspondence: Elisa Carreras Instituto Barraquer, Muntaner, 3|4, Barcelona, Spain 08029 Tel +34616310428 Fax +34932002469 Email elisa.carreras@gmail.com 
The complete pathogenesis of ODP-related maculopathy remains unclear. It is assumed that fluid passes through the ODP and enters the sensory retina creating a schisis-like separation. ${ }^{8-10}$ However, the source of the fluid is controversial. Two major possible sources have been proposed: vitreous cavity or cerebrospinal fluid. ${ }^{11-14}$ Other possible sources are abnormal vessels or vasculature with increased vascular permability. ${ }^{15}$ Some authors have suggested a rhegmatogenous etiology with a small hole or tear in the membrane overlying the pit, which supports the notion that fluid leaks from the vitreous cavity. ${ }^{16,17}$ Based on this hypothesis, our therapeutic approach was to seal the theoretical communication between the vitreous cavity and the retina with autologous platelet concentrate (APC), which has been shown to promote tissue healing and successful results in macular hole surgery, ${ }^{18-22}$ in order to address the etiology of the maculopathy. The purpose of the present study was to evaluate the anatomical and functional results obtained with pars plana vitrectomy (PPV) plus APC and gas tamponade as treatment of ODP-related maculopathy.

\section{Methods}

We performed a prospective interventional study of 19 eyes of 19 consecutive patients with macular detachment associated with congenital ODP, treated between January 2001 and January 2013 at Centro de Oftalmología Barraquer, Barcelona, Spain and Vissum Madrid, Madrid, Spain. All patients had a preoperative visual acuity of 20/40 or worse and no concomitant macular disease.

Preoperatively, we recorded the best corrected visual acuity (BCVA) by logMAR, and intraocular pressure. All patients underwent anterior and posterior segment slit-lamp biomicroscopy, using a 90 diopter noncontact lens, and optical coherence tomography (OCT). The Ethical Committee of clinical research of Centro de Oftalmología Barraquer approval was obtained and informed consent was obtained from all patients.

Surgery was performed by two surgeons, one at each participating center, using three-port 20 or 23 -gauge PPV. The posterior hyaloid was detached to remove any vitreoretinal tractions. The internal limiting membrane (ILM) was not removed in any case. Before fluid-air exchange, careful peripheral fundus examination was performed. Under air, approximately $0.05 \mathrm{~mL}$ of APC was injected over the ODP, sufficient to cover the ODP and the optic disc cup. This was followed by air-15\% perfluoropropane (C3F8) gas tamponade exchange, to expel subretinal and intraretinal fluid and promote reabsorption. Postoperative measures included face-up positioning for 2 hours, to keep the APC in contact with the ODP, and avoidance of the face-up position for the ensuing 10 days, in order to isolate the macula from fluid with long-acting gas. Lens extraction surgery plus intraocular lens implantation was not performed in patients under 50 years of age (number $=16 ; 84.2 \%$ ).

APC was prepared as described by our group in a previous report. ${ }^{23}$ Briefly, blood samples were transferred to a sterile tube containing ethylenediaminetetraacetic acid. The contents were centrifuged at $1,000 \mathrm{rpm}$ for 10 minutes at $10^{\circ} \mathrm{C}$. The lower one-third of plasma, which is rich in platelets, was aspirated and centrifuged again. Part of the plasma was removed, leaving the platelets adhered to the tube walls. The platelets thus obtained were dissolved in saline solution to yield a concentration of $\sim 1,000,000$ platelets $/ \mathrm{mm}^{3}$.

Postoperatively, BCVA and intraocular pressure were recorded; anterior and posterior segment slit-lamp biomicroscopy, using a 90 diopter noncontact lens, and OCT were performed at 1 month, 3 months, 6 months, 9 months, and 12 months, and then annually (spectral-domain Cirrus or Stratus; Carl Zeiss Meditec AG, Jena, Germany). Outcome measures were BCVA, improvement in quality of vision, macular attachment, and resolution of schisis-like intraretinal separation assessed by OCT. BCVA and visual improvement data were statistically analyzed using SPSS version 17 . Results are expressed as the median and range for continuous variables and as the frequency (percentage) for categorical variables. The Wilcoxon test for repeated measures, with $95 \%$ confidence intervals, was used to analyze pre- and postoperative BCVA.

\section{Results}

Nineteen patients (median age: 30 years; range: $13-62$ years; ten women [52.6\%]) were included in the present study. ODP and macular detachment were present in nine right eyes (47.4\%) and ten left eyes (52.6\%) (Table 1).

Preoperatively, all patients had decreased BCVA and 10/19 had associated metamorphopsia during a median of 3 months (range: $0.25-24$ months). Three patients (cases 12,13 , and 14) had previous PPV, laser at the temporal edge of the optic nerve head, and gas tamponade as a first treatment of the ODP-related maculopathy without success. In the preoperative examination, all patients presented with macular detachment associated with ODP. One patient had complete posterior vitreous detachment (PVD), eight patients had incomplete PVD, and the remaining ten patients did not have PVD. The median BCVA was 0.70 (range: 0.30-1.70). The median refractive error was 0 diopters (range: -6.50 to +3.00). OCT showed macular detachment in all cases, with variable degrees of intraretinal schisis-like separation 


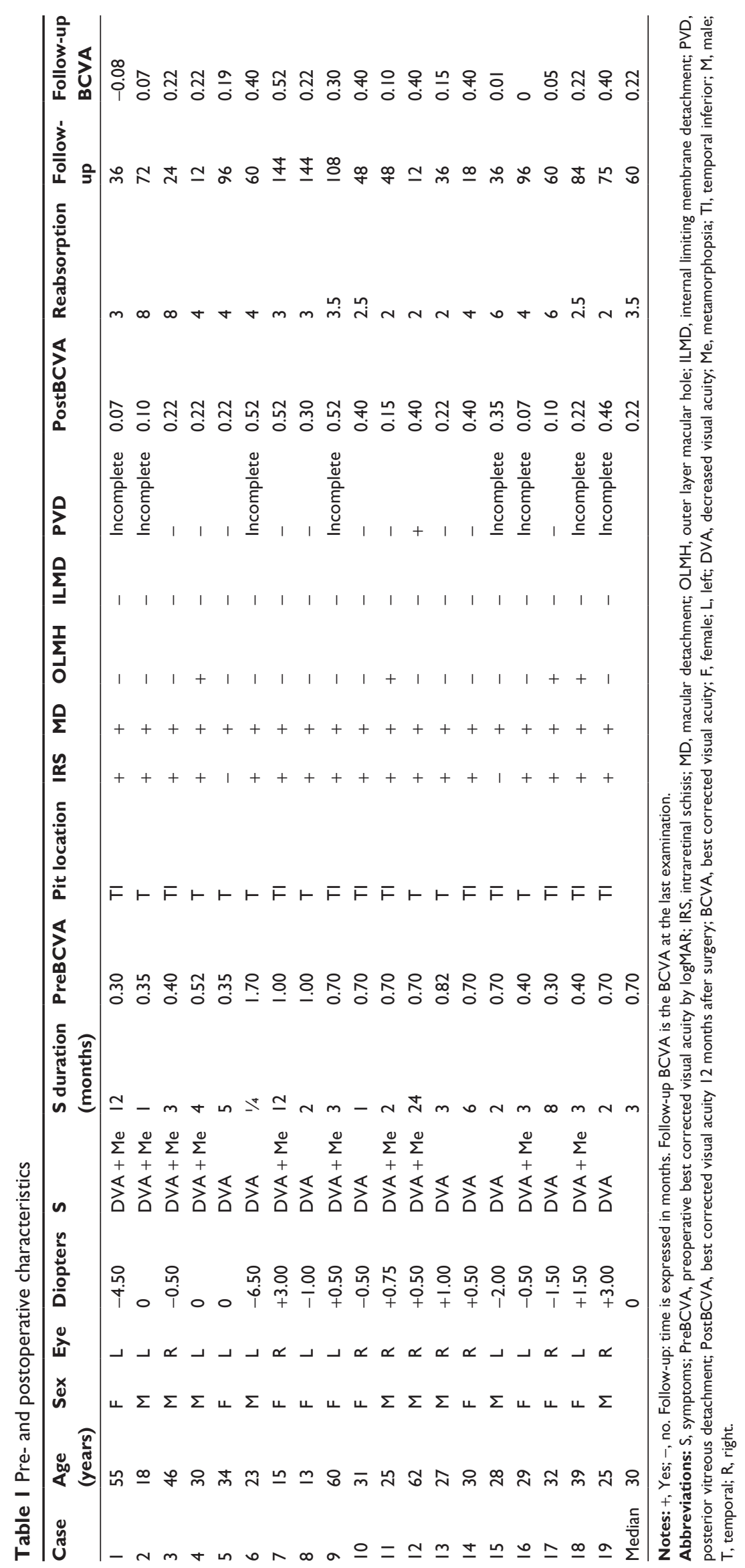


in $17 / 19$ patients $(89.5 \%)$. ILM detachment was not present in any case. Outer layer macular hole was present in 4/19 cases $(21.1 \%)$. In two cases, OCT showed a communication between the vitreous cavity and the retina (Figure 1).

No complications or adverse events were recorded during surgery. Interestingly, in two cases, while the residual vitreous cavity fluid was being removed from the optic disc, the submacular fluid was aspirated through the ODP and the macula was reattached. It was in these two cases where communication between the vitreous cavity and the retina was seen on OCT. No iatrogenic lesions were recorded. Two patients had lens extraction plus intraocular lens implantation at the same surgical time.

The median follow-up was 60 months (range: 12-144 months). Postoperatively, all patients showed improved visual acuity after surgery. The median BCVA was 0.22 (range: 0.07-0.52) at 12-month follow-up, the difference being statistically significant $(P<0.05)$ in comparison with preoperative values. BCVA remained stable in $7 / 19$ cases (36.8\%) and increased in $12 / 19$ cases $(63.2 \%)$ at our last follow-up.

OCT showed complete resolution of intraretinal schisislike separation and macular detachment in all patients (Figure 2). Retinal fluid reabsorption time varied considerably, with a median of 3.5 months (range: $2-8$ months).
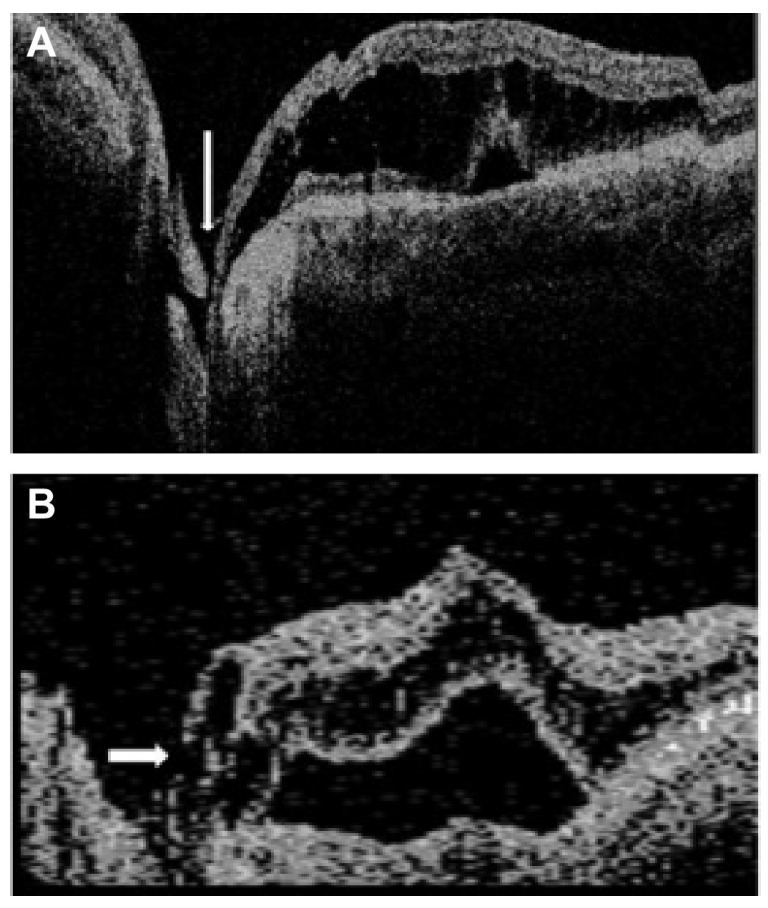

Figure I Optical coherence tomography showing the communication between the vitreous cavity and the retina (arrow) in two different cases.

Notes: Submacular fluid was aspirated during the vitrectomy. (A) Case 12; (B) Case 17.
Minute defects in the outer segment of photoreceptors and/or the inner segment/outer segment lines were observed with high-resolution OCT in all cases.

None of the patients had sight-threatening complications during follow-up. One patient (case 11) presented with inferior exudative vitreous infiltrate, which disappeared 48 hours after surgery without repercussions. None of the patients needed reoperation during follow-up.

\section{Discussion}

ODP maculopathy usually manifests with macular detachment, resulting in visual loss. As reported by Lincoff et $\mathrm{al}^{24}$ macular detachment is associated with a schisis-like separation of the internal retinal layers in almost $90 \%$ of cases. In our study, 17/19 cases presented this separation associated to macular detachment at the first examination. Moreover, four of the 19 cases also presented with an outer layer lamellar macular hole.

Although spontaneous retinal attachment has been described in $25 \%$ of cases, the treatment of nonresolved cases remains controversial and the results are not encouraging. The following therapeutic approaches have been reported: laser therapy, to produce a chorioretinal adhesion barrier at the optic disc border; ${ }^{17,25,26}$ intravitreal gas injection; ${ }^{27}$ PPV with or without laser; ILM peeling; glial tissue removal; and/or air/gas exchange ${ }^{18,20,28-34}$ or macular scleral buckling. ${ }^{35}$

Initially, our group treated ODP-related macular detachment with PPV, a photocoagulation barrier at the temporal optic disc border, plus gas. However, in our revision of 43 eyes, macular detachment persisted in almost 30\% of cases, requiring additional photocoagulation plus gas treatment. After this second treatment, almost $80 \%$ of patients presented with macular attachment. As a result of our poor rates, we developed a new technique based on our experience with APC in macular hole surgery. In this regard, our group has reported successful treatment of recurrent macular detachment secondary to optic nerve coloboma with an overlying retinal hole treated with APC. ${ }^{23}$ This lends support to the hypothesis of a rhegmatogenous etiology to explain submacular fluid associated with both optic nerve head coloboma and ODP. ${ }^{14,36}$

The use of APC was first described by Rosenthal et $\mathrm{al}^{37}$ in a patient with persistent macular detachment due to ODP, after vitrectomy, posterior hyaloid removal, and gas tamponade, with good anatomical and functional results at 3 months of follow-up. However, their technique involved flute needle extraction of the subretinal fluid through the ODP, creating a communication between the vitreous and 

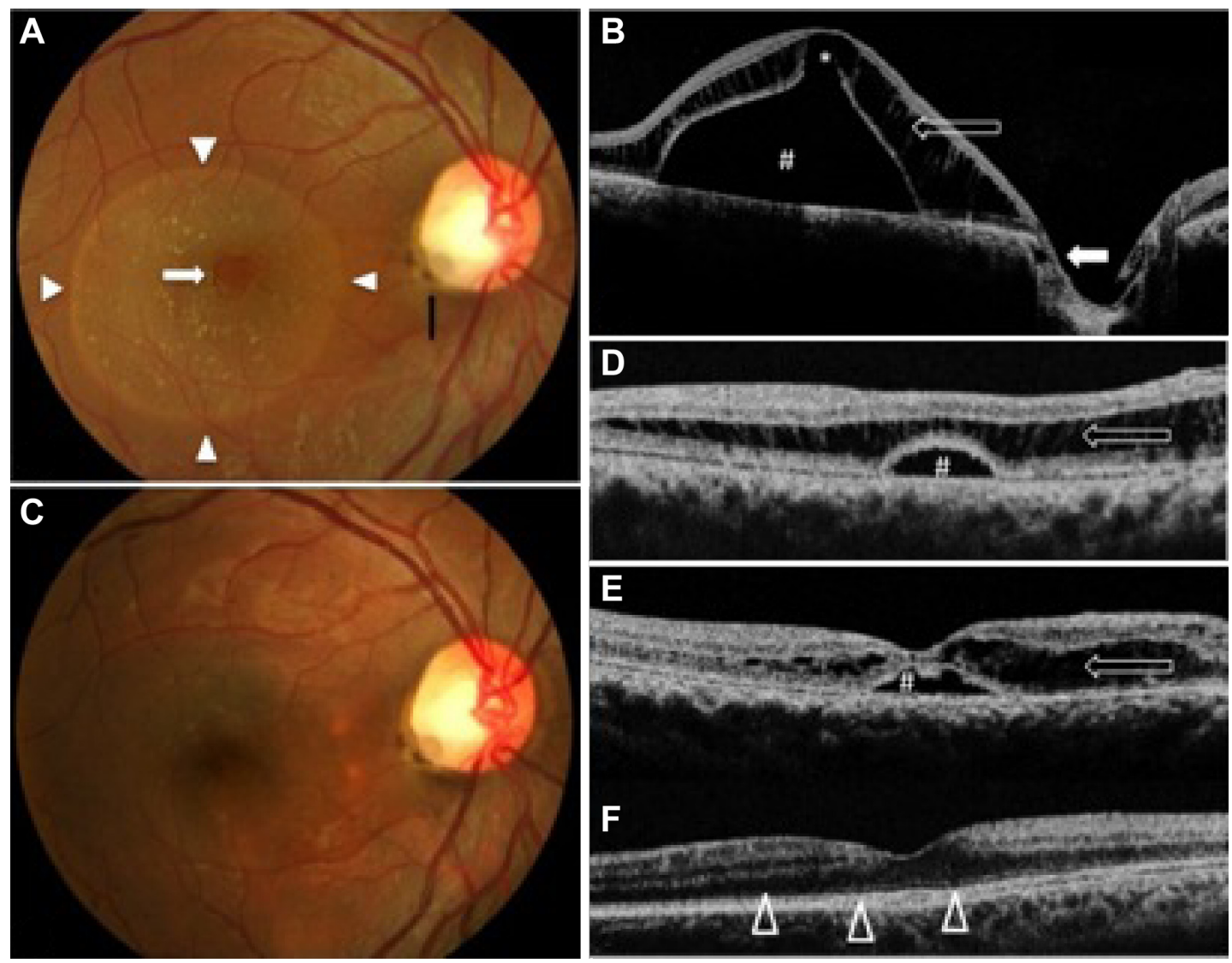

Figure 2 Representative patient, case 17

Notes: (A and B) Posterior segment photograph and OCT preoperatively and (C-F) postoperatively. (A) Fundus examination of the right eye presented an inferotemporal optic disc pit (black arrow) associated with macular detachment (white arrowheads) and an outer layer hole (white arrow). Preoperatively, the BCVA was 0.30 by logMAR. (B) OCT showed macular detachment (\#) with inner retinoschisis separation (arrow) and a lamellar macular hole (open white arrow); note the optic disc pit (white arrow) and communication with the schisis. (D) Postoperatively, the retina showed progressive attachment. At I month after vitrectomy, the inner retinoschisis and the macular detachment decreased, and the lamellar macular hole disappeared. At 3 months, there was (E) residual inner retinoschisis and macular detachment with subretinal precipitates, and (C and $\mathbf{F}$ ) at 6 months, the retina was attached without inner retinoschisis and defects of the inner segment/outer segment line (white open arrowheads), and the BCVA was 0.10 by logMAR.

Abbreviations: OCT, optical coherence tomography; BCVA, best corrected visual acuity.

the subretinal space. Based on the hypothetical rhegmatogenous etiology of ODP-related macular detachment, our technique involves posterior hyaloid peeling to eliminate vitreous-macular traction, and APC injection over the ODP to promote healing of the suspected communication between the ODP and the sensory retina. The possible existence of communication at the level of the ODP is related to epipapillary fibrous tissue traction and incomplete PVD, allowing liquefied vitreous to pass through the ODP and dissect the retina, causing macular detachment or squisis. ${ }^{5,16,17,38}$ As in some cases described by other authors, ${ }^{14-17}$ two of our patients presented with a break in the tissue overlying the ODP, and the vitreous remained attached in both cases, visualized before and during surgery. We believe that the use of APC with its mitogenic and chemotactic properties ${ }^{39}$ associated with posterior hyaloid peeling to eliminate vitreomacular traction, favors the proliferative cellular response and closure of the suspected communication between the vitreous and the retina and, secondarily, promotes reabsorption of intra- and subretinal fluid.

Our technique resulted in improved visual acuity in all cases, with a median gain of four Snellen lines. It also produced stable anatomical and functional improvement during a follow-up period of more than 5 years, without reoperation being required. Such results were not previously obtained by our group with complete PPV, photocoagulation, and gas tamponade alone. Furthermore, reabsorption of intra- and subretinal fluid occurred progressively and was completed within a median time of 4.5 months, which is in contrast to reabsorption times of approximately 1 year reported for other techniques, albeit with good results, such as macular vitrectomy or scleral buckling. ${ }^{33,35}$ This supports the hypothesis of a rhegmatogenous etiology for ODP-related macular detachment, and the use of APC together with the release 
of posterior pole traction allowed us to achieve excellent results.

\section{Conclusion}

In conclusion, our technique with APC to treat ODP-related macular detachment proved highly successful in terms of progressive and stable anatomical and functional improvement. As a promising alternative approach to conventional surgery, it appears to address the etiology of the problem. However, the limited sample size means that this technique requires prospective multicenter studies to confirm its effectiveness.

\section{Acknowledgment}

The study was performed at Centro de Oftalmología Barraquer, Barcelona, Spain and Vissum Madrid, Madrid, Spain.

\section{Author contributions}

All the authors have read and approved the final manuscript submitted.

\section{Disclosure}

The authors report no conflicts of interest in this work.

\section{References}

1. Wiethe T. Ein fall von angeborener. Difformität der Sehnervenpapille. [A case of congenital deformity of the optic disc]. Arch Augenheilkd. 1882;11:14-19. German.

2. Reis W. Eine wenig bekannte typische Missbildung am Sehnerveneintritt: umschriebene Grubenbildung auf der Papilla n. optici. [A littleknown typical malformation on optic disc: localized pitting on the papilla]. Z Augenheilkd. 1908;19:505-528. German.

3. Kranenburg EW. Crater-like holes in the optic disc and central serous retinopathy. Arch Ophthalmol. 1960;64:912-924.

4. Brodsky MC. Congenital optic disk anomalies. Surv Ophthalmol. 1994; 39(2):89-112.

5. Brown GC, Shields JA, Goldberg RE. Congenital pits of the optic nerve head. II. Clinical studies in humans. Ophthalmology. 1980;87(1): $51-65$.

6. Sobol WM, Blodi CF, Folk JC, Weingeist TA. Long-term visual outcome in patients with optic nerve pit and serous retinal detachment of the macula. Ophthalmology. 1990;97(11):1539-1542.

7. Theodossiadis GP, Ladas ID, Panagiotidis DN, Kollia AC, Voudouri AN, Theodossiadis PG. Fluorescein and indocyanine green angiographic findings in congenital optic disk pit associated with macular detachment. Retina. 1999;19(1):6-11.

8. Gass JD. Serous detachment of the macula. Secondary to congenital pit of the optic nervehead. Am J Ophthalmol. 1969;67(6):821-841.

9. Ferry AP. Macular detachment associated with congenital pit of the optic nerve head. Arch Ophthalmol. 1963;70:106-117.

10. Ishikawa K, Terasaki H, Mori M, Sugita K, Miyake Y. Optical coherence tomography before and after vitrectomy with internal limiting membrane removal in a child with optic disc pit maculopathy. Jpn J Ophthalmol. 2005;49(5):411-413.

11. Sugar HS. Congenital pits in the optic disc with acquired macular pathology. Am J Opthalmol. 1962;53:307-311.
12. Sugar HS. An explanation for the acquired macular pathology associated with congenital pits of the optic disc. Am J Ophthalmol. 1964;57: $833-835$.

13. Regenbogen L, Stein R, Lazar M. Macular and juxtapapillar serous retinal detachment associated with pit of optic disc. Ophthalmologica. 1964;148:247-251.

14. Postel EA, Pulido JS, McNamara JA, Johnson MW. The etiology and treatment of macular detachment associated with optic nerve pits and related anomalies. Trans Am Ophthalmol Soc. 1998;96:73-88; discussion 88-93.

15. Gordon R, Chatfield RK. Pits in the optic disc associated with macular degeneration. Br J Ophthalmol. 1969;53(7):481-489.

16. Bonnet M. Serous macular detachment associated with optic nerve pits. Graefs Arch Clin Exp Ophthalmol. 1991;229(6):526-532.

17. Brockhurst RJ. Optic pits and posterior retinal detachment. Trans Am Ophthalmol Soc. 1975;73:264-291.

18. Vote BJ, Membrey WL, Casswell AG. Autologous platelets for macular hole surgery: the Sussex Eye Hospital experience. Clin Experiment Ophthalmol. 2004;32(5):472-477.

19. Paques M, Chastang C, Mathis A, et al. Effect of autologous platelet concentrate in surgery for idiopathic macular hole: results of a multicenter, double-masked, randomized trial. Platelets in Macular Hole Surgery Group. Ophthalmology. 1999;106(5):932-938.

20. Konstantinidis A, Hero M, Nanos P, Panos GD. Efficacy of autologous platelets in macular hole surgery. Clin Ophthalmol. 2013;7:745-750.

21. Castelnovo L, Dosquet C, Gaudric A, Sahel J, Hicks D. Human platelet suspension stimulates porcine retinal glial proliferation and migration in vitro. Invest Ophthalmol Vis Sci. 2000;41(2):601-609.

22. Cheung CM, Munshi V, Mughal S, Mann J, Hero M. Anatomical success rate of macular hole surgery with autologous platelet without internallimiting membrane peeling. Eye (Lond). 2005;19(11):1191-1193.

23. Nadal J, López-Fortuny M, Sauvageot P, Pérez-Formigó D. Treatment of recurrent retinal detachment secondary to optic nerve coloboma with injection of autologous platelet concentrate. J AAPOS. 2012; 16(1):100-101.

24. Lincoff H, Lopez R, Kreissig I, Yannuzzi L, Cox M, Burton T. Retinoschisis associated with optic nerve pits. Arch Ophthalmol. 1988; 106(1):61-67.

25. Theodossiadis GP, Panopoulos M, Kollia AK, Georgopoulos G. Long-term study of patients with congenital pit of the optic nerve and persistent macular detachment. Acta Ophthalmol (Copenh). 1992;70(4): 495-505.

26. Annesley W, Brown G, Bolling J, Goldberg R, Fischer D. Treatment of retinal detachment with congenital optic pit by krypton laser photocoagulation. Graefes Arch Clin Exp Ophthalmol. 1987;225(5): 311-314.

27. Lincoff H, Yannuzzi L, Singerman L, Kreissig I, Fisher Y. Improvement in visual function after displacement of the retinal elevations emanating from optic pits. Arch Ophthalmol. 1993;111(8):1071-1079.

28. Bartz-Schmidt KU, Heimann K, Esser P. Vitrectomy for macular detachment associated with optic nerve pits. Int Ophthalmol. 1995-1996;19(6):323-329.

29. Snead MP, James N, Jacobs PM. Vitrectomy, argon laser, and gas tamponade for serous retinal detachment associated with an optic disc pit: a case report. Br J Ophthalmol. 1991;75(6):381-382.

30. Dai S, Polkinghorne P. Peeling the internal limiting membrane in serous macular detachment associated with congenital optic disc pit. Clin Experiment Ophthalmol. 2003;31(3):272-275.

31. Inoue M, Shinoda K, Ishida S. Vitrectomy combined with glial tissue removal at the optic pit in a patient with optic disc pit maculopathy: a case report. J Med Case Rep. 2008;2:103.

32. Georgalas I, Kouri A, Ladas I, Gotzaridis E. Optic disc pit maculopathy treated with vitrectomy, internal limiting membrane peeling, and air in a 5-year-old boy. Can J Ophthalmol. 2010;45(2):189-191.

33. Hirakata A, Inoue M, Hiraoka T, McCuen BW. Vitrectomy without laser treatment or gas tamponade for macular detachment associated with an optic disc pit. Ophthalmology. 2012;119(4):810-818. 
34. Shukla D, Kalliath J, Tandon M, Vijayakumar B. Vitrectomy for optic disk pit with macular schisis and outer retinal dehiscence. Retina. 2012; 32(7):1337-1342.

35. Theodossiadis GP, Theodossiadis PG. The macular buckling technique in the treatment of optic disk pit maculopathy. Semin Ophthalmol. 2000;15(2):108-115.

36. Gopal L, Badrinath SS, Sharma T, Parikh SN, Biswas J. Pattern of retinal breaks and retinal detachments in eyes with choroidal coloboma. Ophthalmology. 1995;102(8):1212-1217.

37. Rosenthal G, Bartz-Schmidt KU, Walter P, Heimann K. Autologous platelet treatment for optic disc pit associated with persistent macular detachment. Graefs Arch Clin Exp Ophthalmol. 1998;236(2): $151-153$.
38. Theodossiadis PG, Grigoropoulos VG, Emfietzoglou J, Theodossiadis GP Vitreous findings in optic disc pit maculopathy based on optical coherence tomography. Graefes Arch Clin Exp Ophthalmol. 2007; 245(9):1311-1318.

39. Cullinane AB, O'Callaghan P, McDermott K, Keohane C, Cleary PE. Effects of autologous platelet concentrate and serum on retinal wound healing in an animal model. Graefes Arch Clin Exp Ophthalmol. 2002; 240(1):35-41
Clinical Ophthalmology

\section{Publish your work in this journal}

Clinical Ophthalmology is an international, peer-reviewed journal covering all subspecialties within ophthalmology. Key topics include: Optometry; Visual science; Pharmacology and drug therapy in eye diseases; Basic Sciences; Primary and Secondary eye care; Patien Safety and Quality of Care Improvements. This journal is indexed on

Submit your manuscript here: http://www.dovepress.com/clinical-ophthalmology-journal

\section{Dovepress}

PubMed Central and CAS, and is the official journal of The Society of Clinical Ophthalmology (SCO). The manuscript management system is completely online and includes a very quick and fair peer-review system, which is all easy to use. Visit http://www.dovepress.com/ testimonials.php to read real quotes from published authors. 